MIDPI

sciforum
MOL2NET, International Conference Series on Multidisciplinary Sciences

USINEWS-04: US-IN-EU Worldwide Science Workshop Series, UMN, Duluth, USA, 2020

\title{
Facile Synthesis of Natural Therapeutics Encapsulated Biopolymeric Okra Mucilage Nanoparticles as Dual ameliorative agent
}

\author{
Kunal Pal ${ }^{a, b^{*}}$ \\ ${ }^{a}$ Department of Life Science and Biotechnology, Jadavpur University, Kolkata-700032, India. \\ ${ }^{b}$ Division of Molecular Medicine and Centre for Translational Research, Bose Institute, \\ Kolkata-700056, India.
}

\section{*Corresponding author email: kunalpal685@gmail.com}

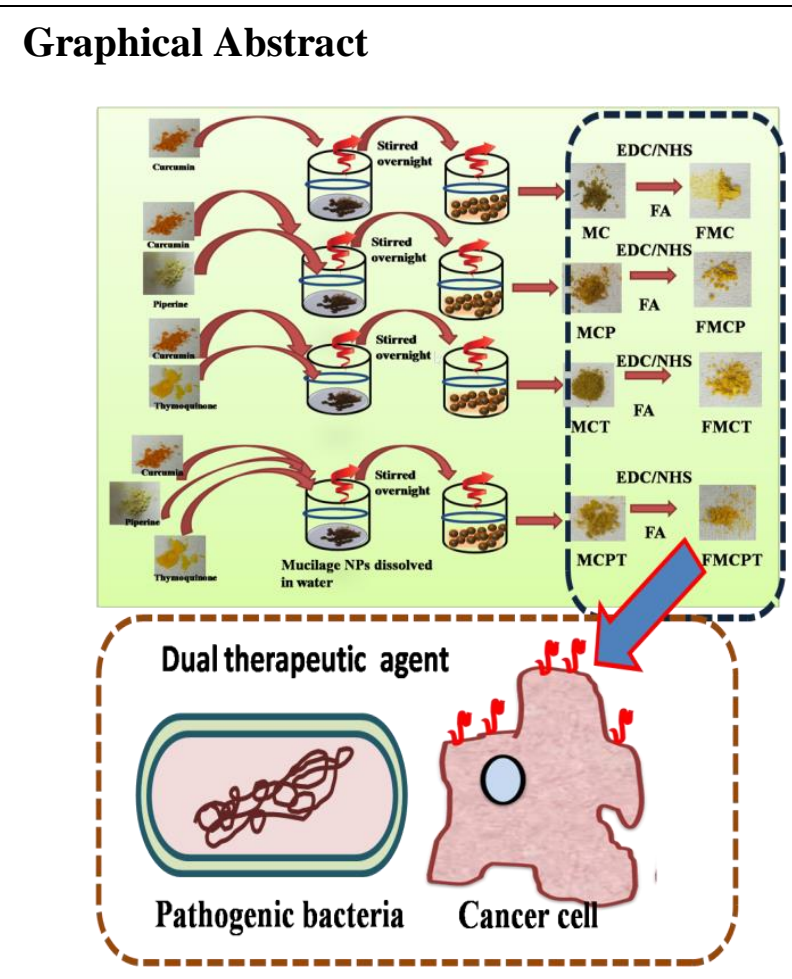

Abstract.

Among the different types of biomaterials, natural excipients Okra mucilage (MNP) is economic and has the potential for controlled drug delivery. We have synthesized MNPs by co-precipitation method and characterized them by XRD, FESEM, FTIR, UV-Vis spectra and DLS. Despite their potential anti-cancer activity, solubility of curcumin, piperine, thymoquinone is very low rendering its limit in application. We have used MNPs where the natural compounds like 
curcumin, piperine, thymoquinone can be loaded comfortably and thereby increases its bioavailability. The antibacterial activity of these nanoparticles were evaluated against pathogenic bacterial strains. The cytotoxicity of curcumin ,piperine, thymoquinone encapsulated MNPs was evaluated on triple negative breast cancer cell lines. They were found to induce apoptosis by perturbing the mitochondrial membrane potential. Folic acid was conjugated to curcumin, piperine, thymoquinone encapsulated MNPs, for delivering it specifically to the breast cancer cells. The antimicrobial and anticancer potential of conjugated and non conjugated MNP were assessed by various in vitro cellular assays. Our present study confirms that these functionacan be used as a dual therapeutic option for combating pathogenic microbial strains and triple negative breast cancer cell.

Keywords-Okra Mucilage; natural therapeutics; synergistic effect; anticancer;antibacterial activities. 


\section{Introduction}

Plant derived polymers such as gums and mucilage have various pharmaceutical applications such as diluents, binder, disintegrant in tablets, thickeners in oral liquids, protective colloids in suspensions, gelling agent in gels, bases in suppository [1]. Mucilages which are found in rhizomes, roots and seed endosperms of various higher plant, may act as energy reserves whereas foliar mucilages do not store carbohydrates [2]. Mucilages are polysaccharide hydrocolloids having high water binding capacity due to the high concentration of hydroxyl groups in the polysaccharides. These polysaccharides are preferred to semi synthetic and synthetic excipients as they are biocompatible, non irritant, lack of toxicity, cheap and easily available [36]. Such a polysaccharide is okra mucilage which can be extracted from okra that is an erect annual plant, botanically known as Abelmoschus esculentus (Family: Malvaceae). Okra mucilage is a polymer of galacturonic acid, rhamnose, and galactose [7]. It can be used as a pharmaceutical excipient i.e. binder, film coating, bio-adhesive and suspending agent [8].

Recent studies show that various kind of natural products have potent medicinal properties and can be used to treat many diseases. One of those natural products is Curcumin (MW 368.38 $\mathrm{g} / \mathrm{mol}$ ) derived from the plant Curcuma longa is slightly soluble in water and it has great role in different type of diseases such as cancer, diabetes, arthritis, atherosclerosis and auto immune diseases $[9,10]$ as well as it has antibacterial activity too [11]. One of the very useful medicinal properties of curcumin is its anticancer efficacy. It inhibits tumor progression by activating cell signals and inducing apoptosis in pre-cancerous or cancer cells without affecting normal cells [12-15]. But, its poor water solubility restricts its therapeutic use in cancer treatment $[16,17]$. 
Thymoquinone (MW164.2 g/mol) is a phytochemical present in black cumin Nigella sativa with a long history of medicinal use [18]. It has anti microbial, anticancer, anti diabetic, analgesic, anti inflammatory and antioxidant activities [19-21].

Piperine (MW285.34 g/mol) is another natural product having good anticonvulsant, anti microbial and anticancer property [22, 23]. It is a plant alkaloid found in black pepper Piper nigrum and long pepper Piper longum. It is reported that piperine has bioavailability enhancing activity for some drug $[24,25]$.

From the therapeutic approach various strategies have been employed to minimize the toxicity to normal cells. Many kinds of cancer targeting agents like small molecules (folic acid, benzamides), peptides (RGD, EGF), peptide domain (FN3 domain, $\mathrm{Z}$ domain) are reported [2628]. Among them folic acid is one of the well accepted cancer targeting agent due to its low cost and it is easy to modify. Folate receptors are over expressed in a variety of cancer cells like epithelial, ovarian, cerviacal, lung [29, 30]. Additionally, these folate receptors are either absent or expressed at a low level in normal cells, which makes them an ideal targeting agent. Thus folate receptors can be employed as effective tool for active targeting of various drug delivery systems.[31]

Here we have evaluated the effect of these natural compound encapsulated biopolymeric mucilage nanoparticles on the prokaryotic and eukaryotic systems. The Curcumin-PiperineThymoquinone encapsulated biopolymeric Okra mucilage nanoparticles (MCPT) had more promising effect against Gram-positive (S. aureus) and Gram-negative (E. coli) pathogenic bacterial species than curcumin or curcumin and piperine or curcumin and thymoquinone encapsulated mucilage nanoparticles (MC,MCP,MCT respectively) due to their synergistic effects. 
The natural compounds like curcumin, piperine and thymoquinone are reported to possess significant anticancer activities. The encapsulation of these natural compounds within the bioplymeric Okra mucilage matrix enhances their bioavailability. Furthermore the mucilage nanoparticles were conjugated with folic acid in order to target these natural compounds specifically towards the folate receptor over expressed breast cancer cell lines. Our results suggests that the Curcumin-Piperine-Thymoquinone encapsulated folic acid conjugated bioplymeric Okra mucilage nanoparticles (FMCPT) had more promising effect against the breast cancer cell lines than folic acid conjugated curcumin or curcumin and piperine or curcumin and thymoquinone encapsulated mucilage nanoparticles (FMC,FMCP,FMCT) and the non conjugated nanoparticles(MC, MCP, MCT, MCPT) due to their synergistic effects. Our results suggest that the Reactive oxygen species (ROS) generation plays a crucial role in the maintenance of the redox balance in most cancer cells and an elevated ROS level may promote oxidative damage which in turn leads to the mitochondrial membrane potential disruption that culminates in cellular abnormalities or death [32].

In this study, we investigated their antimicrobial as well as anticancer activities against different pathogenic bacterial strains and MDA-MB 468 breast cancer cell lines. Thus, the development of these biopolymeric, non hazardous, eco-friendly functionalized natural compound encapsulated mucilage nanoparticles has the potential to emerge as an effective dual therapeutic agent. 


\section{Method}

\subsection{Material}

Okra had been collected from market and mucilage was extracted. Ethanol was purchased from Merck. LB broth, Agar powder were supplied by HiMedia. Curcumin, Thymoquinone, Piperine were purchased from Sigma-Aldrich, Cell culture DMEM, RPMI, Fetal Bovine Serum (FBS), JC-1 (mitochondrial staining dye), N-hydroxysuccinimide (NHS), 1-[3-dimethylamino)propyl]-3-ethylcarbodiimide hydro-chloride (EDC), Thiazolyl blue formazan (MTT), and 2',7'-Dichlorofluorescin diacetate (DCF-DA), were purchased from Sigma-Aldrich. Deionised (Millipore) water was used throughout the experiment with resistivity at least $18 \mathrm{M} \Omega$. All glassware used was cleaned with aqua regia solution followed by rinsing with ultrapure Millipore water.

\subsection{Bacterial Strains:}

Standard cultures for antibacterial assays were procured from Microbial Type Culture Collection (MTCC), IMTECH, Chandigarh, India. These include Gram-positive (Staphylococcus aureus 740 and Bacillus subtilis 441) and Gram-negative (Escherichia coli 443 and Pseudomona aeruginosa1688)

\subsection{Breast cancer cell line}

Triple negative breast cancer cell line, MDA-MB-468 were obtained from the central cell repository of National Center for Cell Science (NCCS), Pune, India and cultured as suggested by the supplier. . All the above cell lines were cultured either in RPMI 1640 or DMEM, containing $10 \%$ FBS, 1mM sodium pyruvate, 2mM L-glutamine, non-essential amino acids, 100 units/L penicillin, 100mg/L streptomycin and $50 \mathrm{mg} / \mathrm{L}$ gentamycin sulfate at $37^{\circ} \mathrm{C}$ with $5 \% \mathrm{CO}_{2}$.

\subsection{Extraction mucilage from Okra}

About $500 \mathrm{~g}$ of fresh okra was collected from market and washed with distilled water. After washing these were chopped into small pieces and kept in beakers containing $500 \mathrm{ml}$ of water, then stirred continuously until the mixture became concentrated. Then, the concentrated solution was filtered through strainer. After that, absolute ethanol was added to the filtered solution in continuous stirring condition. Due to ethanol treatment mucilage got precipitated. Precipitated mucilage was collected in a 
petridish and kept at $37^{\circ} \mathrm{C}$ for overnight to make it dry. On the very next day the dried mucilage was grinded with mortar pestle and now this grinded mucilage is ready to be used .

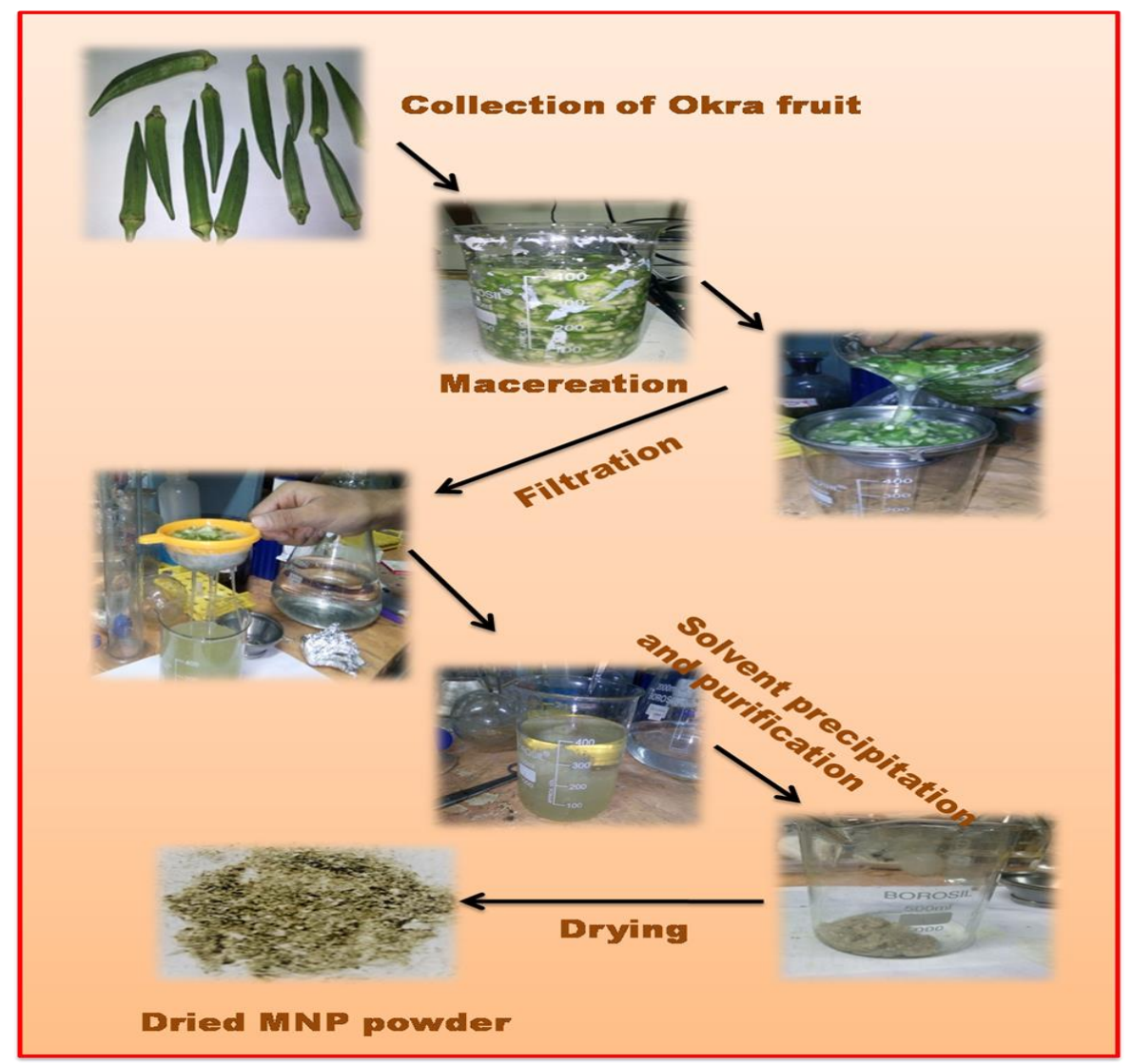

Figure.1. Schematic representation for the synthesis of Okra Mucilage nanoparticles

\subsection{Drug loaded mucilage synthesis}

$10 \%$ of total weight (drug+mucilage) should be the weight of a drug to be loaded e.g. if we want prepare $100 \mathrm{mg}$ of drug loaded mucilage and there are two drugs then $10 \mathrm{mg}$ of each drugs and $80 \mathrm{mg}$ of mucilage would be taken.

To prepare curcumin loaded mucilage (MC), $90 \mathrm{mg}$ of mucilage was dissolved in $20 \mathrm{ml}$ water and vigorously stirred using a magnetic stirrer for 24 hour. After 24 hour, 10mg of curcumin, was added to the mucilage solution. Similarly 10mg each of curcumin, piperine and curcumin, thymoquinone were added to $80 \mathrm{mg}$ mucilage solution to prepare curcumin-piperine and curcumin-thymoquinone loaded 
mucilage(MCP and MCT) resepectively. To prepare curcumin-piperine-thymoquinone loaded mucilage (MCPT), $10 \mathrm{mg}$ of each drugs were added to $70 \mathrm{mg}$ mucilage solution prepared through above described process.

\subsection{Folic acid conjugated drug loaded mucilage synthesis}

At first, $8 \mathrm{mg}$ of folic acid and $1 \mathrm{mg}$ each of EDC and NHS was added in 20ml acetone in dark condition to activate the folic acid. The activated folic acid was then drop wise added to $20 \mathrm{ml}$ drug loaded mucilage solution containing 90mg drug loaded mucilage and the whole solution was stirred overnight with the help of magnetic stirrer in dark condition. After that, the reaction mixture was centrifuged at $8000 \mathrm{rpm}$ for $8 \mathrm{~min}$ and the supernatant was discarded and folic acid conjugated drug loaded mucilage was dissolved in minimum amount of water. Then the solution was taken in a petridish and kept in $37^{\circ} \mathrm{C}$ to make dry it. Finally the dried material was collected.

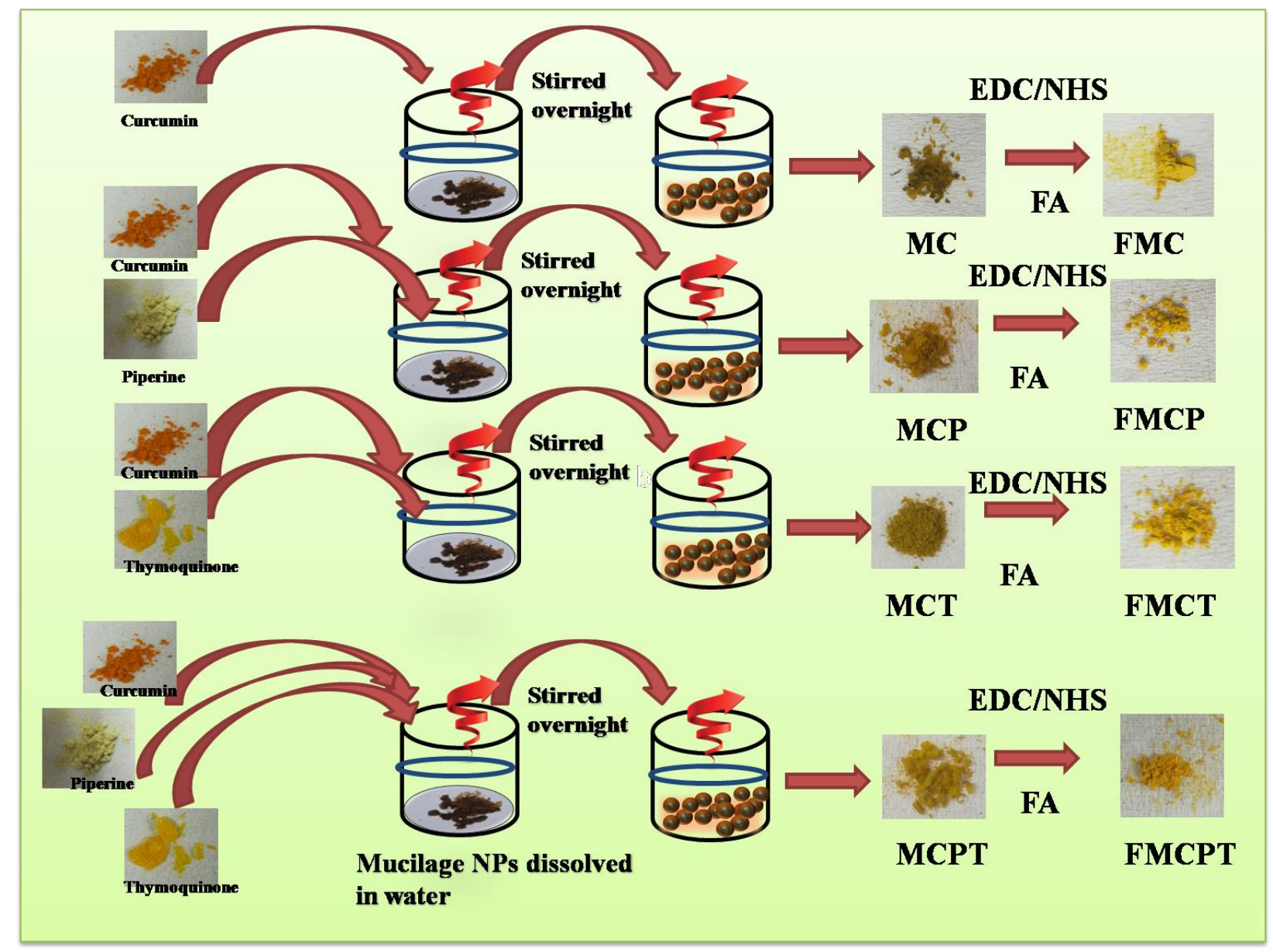

Figure.2. Schematic representation of the encapsulation of natural therapeutics into the Okra mucilage nanoparticles 


\subsection{Characterization of Okra mucilage nanoparticles}

The XRD (X Ray Diffractometer) patterns of the powdered Okra mucilage samples were recorded by X-ray powder diffractometer model-D8, Bruker AXS, Winconsin, USA, using $\mathrm{Cu}-\mathrm{K} \alpha$ target employing wavelength of $1.5418 \AA$ and operating at $35 \mathrm{kV}$ with scan speed of $1 \mathrm{sec} / \mathrm{step}$. Field emission scanning electron microscope (FESEM) was employed for morphological study using INSPECT F50 (FEI, Netherland). The Fourier transform infrared spectroscopy (FTIR) study was done using FTIR8400 S, Shimadzu in the wave number range from $400 \mathrm{~cm}^{-1}$ to $4000 \mathrm{~cm}^{-1}$. The Okra mucilage nanoparticles were dispersed in MilliQ water to form a diluted suspension of $2 \mathrm{mg} / \mathrm{ml}$ using a bath sonicator for 30 mins. When particles were completely dispersed in water its absorption spectra was taken using UV visible spectrophotometer (Bio-Tek). Average particle diameter and size distribution of Okra mucilage nanoparticles were measured DLS (Dynamic light Scattering) using Zetasizer (NANO ZS90, Malvern Instruments Ltd,UK). The charge of the NP was also measured by the Zetasizer.

\subsection{Minimum Inhibitory Concentration (MIC) determination}

Test tubes containing $4 \mathrm{ml}$ of LB media was inoculated with $200 \mu$ l overnight culture of E.coli (DH5 $)$ and S.aureus for 4 hour. Then various concentrations $(100 \mu \mathrm{g} / \mathrm{ml}, 200 \mu \mathrm{g} / \mathrm{ml}, 300 \mu \mathrm{g} / \mathrm{ml}$, $400 \mu \mathrm{g} / \mathrm{ml}$ and $600 \mu \mathrm{g} / \mathrm{ml}$ ) of drug loaded mucilages was added to each marked tubes. Tubes were then left for shaking at $37^{\circ} \mathrm{C}$ for 24 hour. After 24 hour OD of each solution were measured at $600 \mathrm{~nm}$.

\subsection{Agar well diffusion method}

The susceptibility of pathogenic bacteria to Okra mucilage MC, MCP, MCT, MCPT nanoparticles was examined by the Agar well diffusion method according to a previously reported protocol. The pathogenic strains were grown on $\mathrm{LB}$ Broth at $37^{\circ} \mathrm{C}$ overnight upto a turbidity of 0.5 Mac Farland standards $\left(10^{8} \mathrm{CFU}\right.$ per $\left.\mathrm{ml}\right)$. About $100 \mu \mathrm{l}$ of this suspension was used to inoculate $90 \mathrm{~mm}$ diameter petridish filled with $30 \mathrm{ml}$ of LB Agar. Wells were punched in the Agar plates and treated with Okra mucilage MC, MCP, MCT, MCPT nanoparticles at their MIC concentrations. The zone of inhibition diameter in the bacterial growth surrounding the disc (excluding the well) was measured. 


\subsection{Cytotoxicity assay}

The viability of MDA-MB 468 cells after exposure to various concentrations of natural compound encapsulated folic acid conjugated and non conjugated Okra mucilage nanoparticles was determined by 3(4,5-dimethylthiazol-2-yl)-2,5-diphenyltetrazolium bromide (MTT) assay. Briefly, around $1 \times 10^{4}$ cells per well of 48-well plates were exposed to Okra mucilage capped natural compound encapsulated nanoparticles at the concentrations of untreated as control, 20,40, 60, 80, $100 \mu \mathrm{g} / \mathrm{ml}$ for $24 \mathrm{~h}$ of incubation at $37 \circ \mathrm{C}$ and $5 \% \mathrm{CO} 2$. Following this, the cells were incubated $\mathrm{Zn}$ aiwith $10 \mu \mathrm{MTT}$ solution (stock $1 \mathrm{mg} / \mathrm{ml}$ ) for $4 \mathrm{~h}$ at $37 \circ \mathrm{C}$ and $5 \% \mathrm{CO}_{2}$ following a wash with $1 \times$ phosphate-buffered saline (PBS), and the resulting formazan crystals were dissolved in MTT solubilization buffer to measure the absorbance at $570 \mathrm{~nm}$ by using a microplate reader (Biorad). The data were formulated comparing with the control ones $[33,34]$.

\subsection{ROS measurement Intracellular ROS generations were checked by DCFDA method}

Normally, the DCFDA enters the cell and reacts with the reactive oxygen to give a green fluorescent color compound dichlorofluorescein (DCF) [33]. Briefly, a stock solution of DCFDA (10 mM) was prepared in methanol and was further diluted with PBS to a working concentration of $100 \mu \mathrm{M}$. MDA-MB 468 cells were treated at $\mathrm{LD}_{50}$ dose of MCPT and FMCPT for $12 \mathrm{~h}$ at $37{ }^{\circ} \mathrm{C}$, and washed with ice-cold $1 \times$ PBS followed by an incubation with $100 \mu \mathrm{M}$ of DCFDA for $30 \mathrm{~min}$ in the dark at $37{ }^{\circ} \mathrm{C}$. The fluorescence intensity was measured both spectroscopically (Hitachi, Japan) and under a fluorescence microscope in MDA-MB-468 cells (Leica, Japan) at excitation and emission wavelengths of 485 and $520 \mathrm{~nm}$, respectively.

\subsection{Mitochondrial membrane potential measurement by JC1 staining}

Mitochondria depolarization is specifically indicated by JC-1 dye, which is a cationic dye that exhibits potential-dependent accumulation in mitochondria, indicated by a fluorescence emission shift 
from red to green as the mitochondrial membrane gets damaged and loses its membrane potential [33]. Cells were treated after the respective $\mathrm{LD}_{50}$ dose of MCPT and FMCPT nanoparticles for $12 \mathrm{~h}$. After the treatment, the cells were washed with phosphate buffered saline (PBS) and incubated with (10 $\mu \mathrm{g} / \mathrm{ml}) \mathrm{JC}$ 1 for $30 \mathrm{~min}$ at $37^{0} \mathrm{C}$. Cells were then observed under a fluorescence microscope (Leica, Wetzlar, Germany).

\section{Results and discussions-}

\subsection{Structural morphology analysis of Okra mucilage Okra mucilage nanoparticles}

The XRD pattern of GA and MCPT are shown in Fig. 1(XRD). In the XRD spectrum of MNPs, no crystalline peaks are observed, but a small hump $\left(25-40^{\circ}\right)$ is seen in MCPT. This confirms the encapsulation of curcumin, piperine, thymoquinone in the cross-linked network of MNPs.

Morphology and particle size of the samples were determined using FESEM. FESEM micrographs [Fig. 1(FESEM)] show spherical distribution of the particles with a size range of 400- $500 \mathrm{~nm}$ (for MNP).

\subsection{Spectroscopic analysis of Okra mucilage nanoparticles}

FTIR spectroscopy is a useful technique to examine the functional groups of any organic molecule. Formation of drug loaded mucilage and conjugation of folic acid (FA) with drug loaded Okra mucilage was confirmed by FTIR study. Fig. 1(FTIR) showed that the pure MNPs exhibit strong band at $3407 \mathrm{~cm}^{-1}$ (-OH stretching) and $2937 \mathrm{~cm}^{-1}$ (-CH stretching). Vibrational peaks at 1624 and $1427 \mathrm{~cm}^{-1}$ (symmetric and asymmetric stretching of -COO-) indicate the formation of Okra mucilage[23]. Conjugation of curcumin, piperine, thymoquinone with Okra is indicated by a peak at $1510 \mathrm{~cm}^{-1}(\mathrm{C}-\mathrm{C}$ stretching) and $1627 \mathrm{~cm}^{-1}$ (-C=O vibration) [23]. The FTIR spectra of MCPTF Okra mucilage nanoparticles showed two clear absorbance $1125 \mathrm{~cm}^{-1}$ and $1605 \mathrm{~cm}^{-1}$ which are similar to the absorbance peak present in FA. These results confirm the conjugation of folic acid modified and curcumin, piperine, thymoquinone loaded MNPs.

Ultraviolet-visible spectroscopy is a characterizing tool to ascertain the optical behaviour of a material. The absorbance spectrum of MNP [fig 1(UV-Vis analysis)] does not show any sharp peak in its spectrum whereas MC, MCP, MCT and MCPT samples exhibit a prominent peak at $423 \mathrm{~nm}, 343 \mathrm{~nm}, 430$ 
$\mathrm{nm}$ and $344 \mathrm{~nm}$ respectively [35,36]. There is a hump at $425 \mathrm{~nm}$ in MCP and MCPT UV spectra due to presence Curcumin [37]
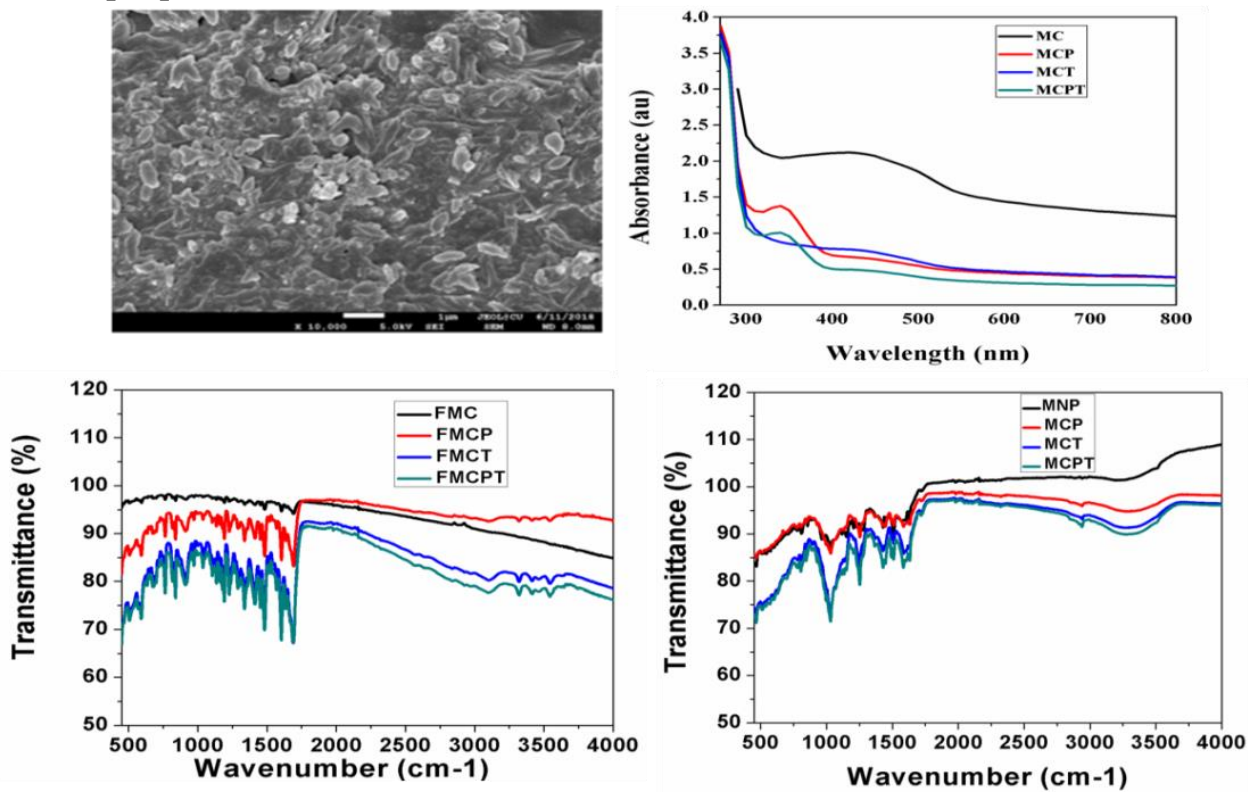

Figure.3. Physical characterizations of the Okra mucilage nanoparticles.

\subsection{Colloidal performance and surface charge of synthesized Okra mucilage nanoparticles}

Curcumin, piperine, thymoquinone loaded MNPs show a hydrodynamic diameter of $413.3 \mathrm{~nm}$ and a zeta potential of $-0.348 \mathrm{mV}$ (Table. 1). Curcumin, piperine, thymoquinone loading does not alter the zeta potential, but increases the hydrodynamic diameter. Presence of curcumin, piperine, thymoquinone inside the matrix also increases the size of the Okra mucilage nanoparticles than the bare Okra mucilage nanoparticles. The folic acid conjugation enhances the hydrodynamic diameter of the Okra mucilage nanoparticles to $813.3 \mathrm{~nm}$ and the surface charge of the Okra mucilage nanoparticles considerably increases to $-7.6 \mathrm{mV}$. This high negative zeta potential of the Okra mucilageindicates the stability of the particles. The corresponding polydispersity index (PDI) values of the samples are quite low suggesting that they form a homogenous solution which is desirable for any biological application.
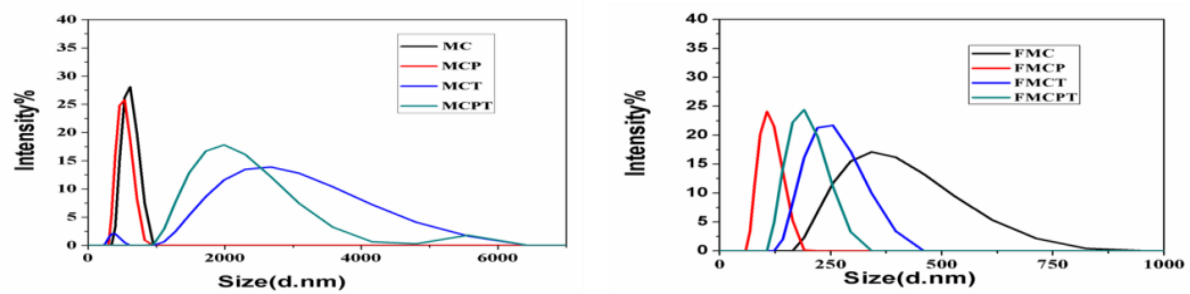

\begin{tabular}{|l|l|l|l|}
\hline Sample Name & PDI & D1.SSize (d. . nm) & Zeta Potential (mV) \\
\hline MC & 0.299 & 605.2 & 1.100 \\
\hline MCP & 0.193 & 617.3 & 0.219 \\
\hline MCT & 0.314 & 1887 & -0.424 \\
\hline MCPT & 0.278 & 2066 & -2.640 \\
\hline FMC & 0.157 & 340.6 & -2.580 \\
\hline FMCP & 0.015 & 105.9 & -3.160 \\
\hline FMCT & 0.005 & 236.3 & -1.460 \\
\hline FMCPT & 0.061 & 185.4 & 0.365 \\
\hline
\end{tabular}




$\begin{array}{lll}\text { Sample name } \quad \text { E.coli } & \text { S.aureus }\end{array}$

Figure.4. Hydrodynamic size and Zeta potential studies of MC,MCP,MCT,MCPT,FMC,FMCP, FMCT,FMCPT.

\subsection{Biopolymeric MC, MCP, MCT, MCPT nanoparticles nanoparticles exhibits significant} antibacterial activity against pathogenic bacterial strains

To evaluate the bactericidal activity of the synthesized MC, MCP, MCT, MCPT nanoparticless have been treated separately against Gram negative E.coli and Gram positive S.aureus. In the case of E.coli, strain the $\mathrm{IC}_{50}$ values of MC, MCP, MCT, MCPT nanoparticles was $240 \pm 2.7 \mu \mathrm{g} / \mathrm{ml}, 224 \pm 3.5 \mu \mathrm{g} / \mathrm{ml}$, $218 \pm 4.1 \mu \mathrm{g} / \mathrm{ml}$ and $176 \pm 2.89 \mu \mathrm{g} / \mathrm{ml}$, that is in case of S.aureus the MIC values were $236 \pm 2.67 \mu \mathrm{g} / \mathrm{ml}$, $218 \pm 3.65 \mu \mathrm{g} / \mathrm{ml}, 215 \pm 2.98 \mu \mathrm{g} / \mathrm{ml}$ and $163 \pm 2.57 \mu \mathrm{g} / \mathrm{ml}$, respectively.

In this study we observed significant bactericidal activity of all the natural compound encapsulated Okra mucilage nanoparticles. However, the Curcumin-Piperine-Thymoquinone encapsulated bioplymeric Okra mucilage nanoparticles (MCPT) had more promising effect against Gram-positive (S. aureus) and Gramnegative (E. coli) pathogenic bacterial species than single compound encapsulated mucilage nanoparticles (MC,MCP,MCT) due to their synergistic effects [fig 5]

E. Coli
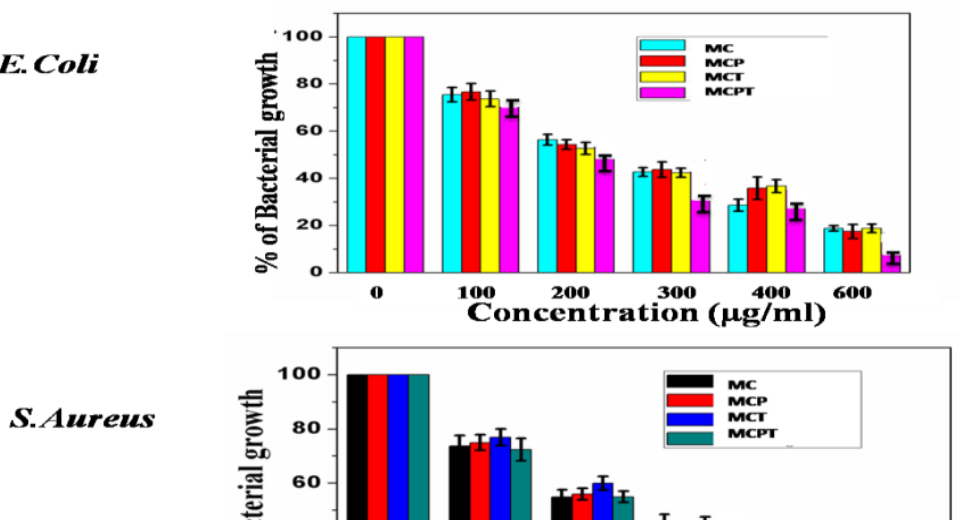

Figure.5. Synergistic effects of natural therapeutics encapsulated Okra mucilage nanoparticles on common pathogenic bacterial strains 


\begin{tabular}{|lcc|}
\hline MC & $240 \pm 2.7$ & $236 \pm 2.67$ \\
\hline MCP & $224 \pm 3.5$ & $218 \pm 3.65$ \\
\hline MCT & $218 \pm 4.1$ & $215 \pm 2.98$ \\
\hline MCPT & $176 \pm 2.89$ & $163 \pm 2.57$ \\
\hline
\end{tabular}

\subsection{Bactericidal activity of MC, MCP, MCT, MCPT nanoparticles confirmed by Disc diffusion method}

This study was performed to visualize the comparison of antibacterial activity of different Okra mucilage capped MC, MCP, MCT, MCPT nanoparticles. The zone of inhibitions against the Grampositive and Gram negative bacteria are shown in Figure 6. Zone of inhibition having a radii of around $1.16 \pm 0.04 \mathrm{~cm}, 1.86 \pm 0.23 \mathrm{~cm}, 1.94 \pm 0.44 \mathrm{~cm}, 2.14 \pm 0.40 \mathrm{~cm}$ ( in case of E.coli) and $0.91 \pm 0.12 \mathrm{~cm}$, $1.23 \pm 0.04 \mathrm{~cm}, 1.19 \pm 0.04 \mathrm{~cm}, 1.45 \pm 0.07 \mathrm{~cm}$ (in case of S.aureus) were observed when strains were treated $\mathrm{MC}, \mathrm{MCP}, \mathrm{MCT}$, MCPT respectively nanoparticles at their respective $\mathrm{IC}_{50}$ values. So, from this study, it is quite evident that the MC, MCP, MCT, MCPT nanoparticles are really proved to be beneficial and can be administered for pathogenic E.coli and S.aureus, growth inhibition with MCPT having the more pronounced effect.

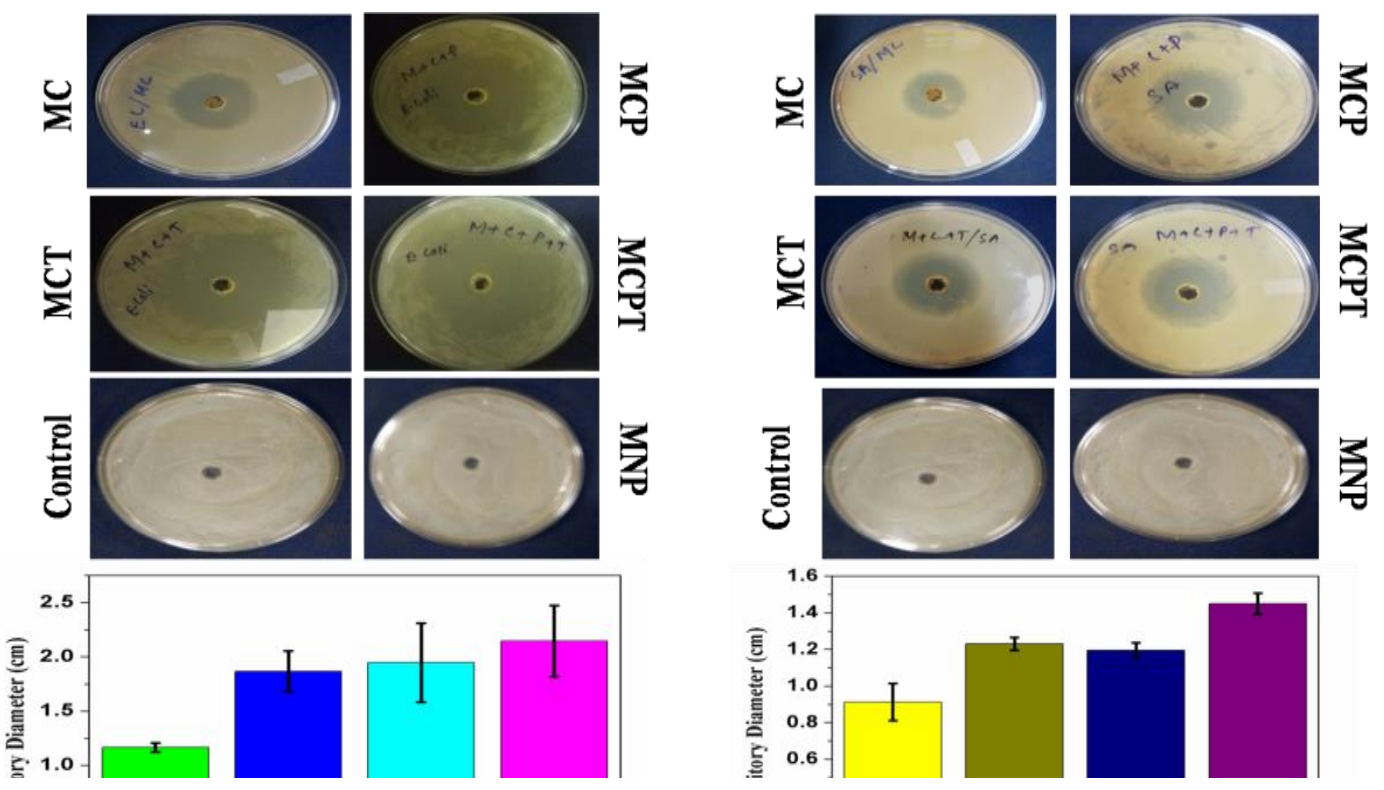

Figure.6. Bactericidal activity of natural compound encapsulated Okra mucilage nanoparticles confirmed by Disc diffusion method 
3.6. Selective cytotoxicity of targeted Okra mucilage Okra mucilage nanoparticles towards the folate overexpressed TNBC cells

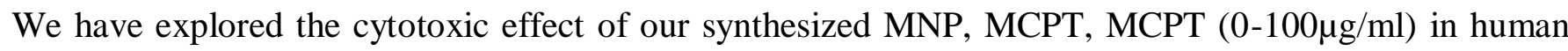
triple negative breast cancer cell lines MDA-MB 468 respectively. It was found that cell survivability was decreased in dose dependent manner in the treated cells. This study concluded that FMCPT have strong cytotoxic effect on both human TNBC as compared to MNP, MCPT [Fig 7]. Bare Okra mucilage nanoparticles have little cytotoxic effect. The $\mathrm{LD}_{50}$ dose for each of these Okra mucilage nanoparticles are compared in Table 3. Our results suggests that The Curcumin-Piperine-Thymoquinone encapsulated folic acid conjugated bioplymeric Okra mucilage nanoparticles (FMCPT) had more promising effect against the breast cancer cell lines than single compound encapsulated folic acid conjugated mucilage nanoparticles (FMC,FMCP,FMCT) and the non conjugated nanoparticles(MC, MCP, MCT, MCPT).
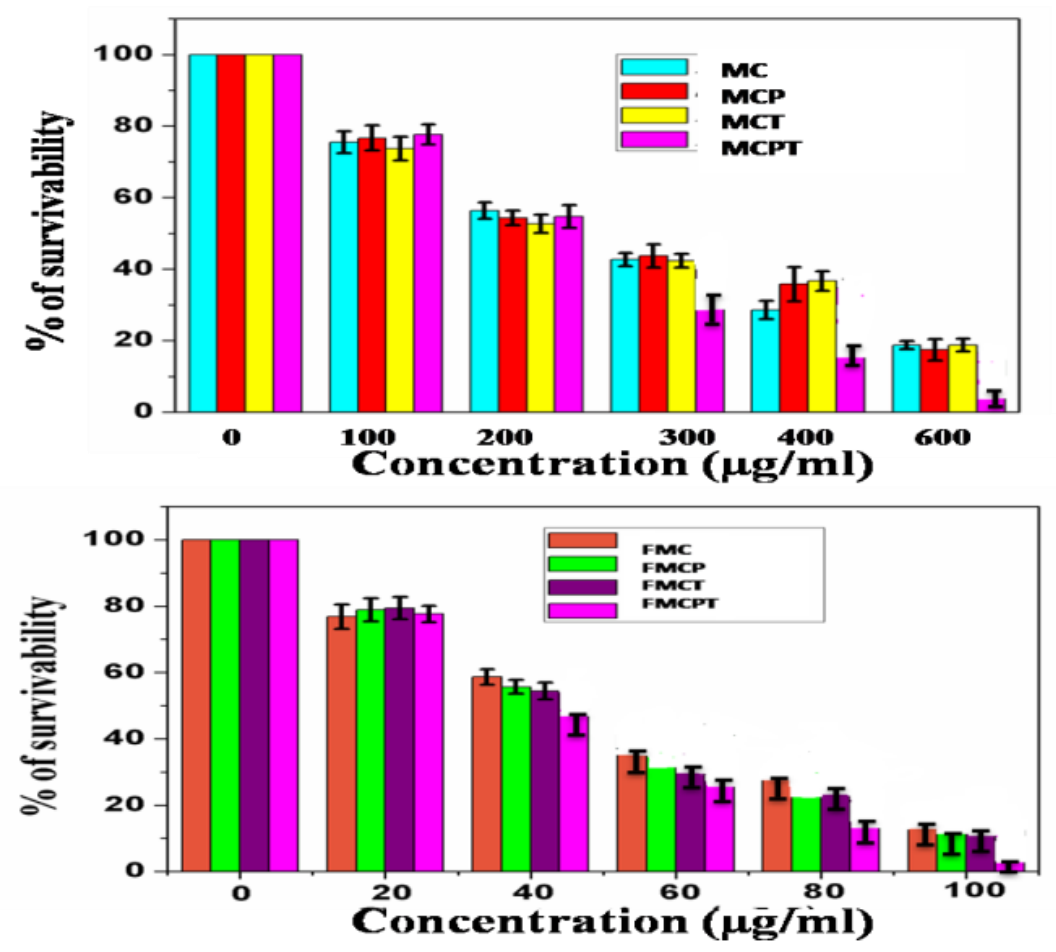

Figure.7.Selective and synergistic effects of the natural compound encapsulated folic acid conjugated MNPs in MDA-MB 468 cells 


\subsection{Treatment of targeted curcumin, piperine, thymoquinone encapsulated Okra mucilage} nanoparticles promotes ROS generation and mitochondrial permeability transition (MPT) in TNBC cells.

Reactive oxygen species (ROS) was measured by both fluorescence microscopy and spectrofluorometry methods by using specific probe, DCF-DA. MDA-MB 468 cells were used for the determination of reactive oxygen production .The cells were treated with MNP, MCPT, FMCPT treatment at their respective $\mathrm{LD}_{50}$ dose for $12 \mathrm{~h}$. From the fluorescence microscopic image, it was seen that green color fluorescent intensity was increased for FMCPT treated cells in MDA-MB 468 cell line compared to control cells (Fig. 8a). From the spectrofluorometry study, it was seen that ROS intensity increased almost 2.5 folds for the cell line in FMCPT treated cells (Fig. 8b).

a

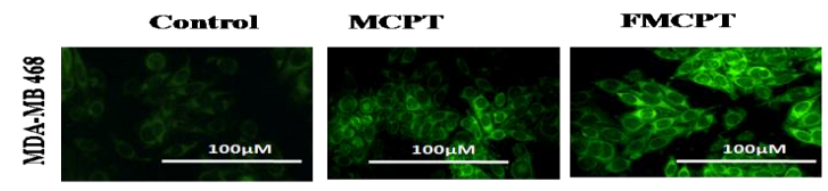

b

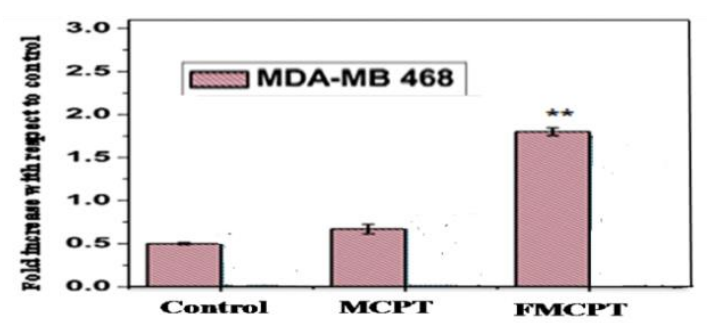

Figure.8.Enhancement of intracellular oxidative stress in MDA-MB 468 cells

Production of ROS directly contributes to mitochondrial damage. Thus, we explored the mitochondrial membrane potential effect of FMCPT, MCPT in MDA-MB 468 cells. Mitochondria depolarization is specifically indicated by JC-1 dye, which is a cationic dye that exhibits potential-dependent accumulation in mitochondria, indicated by a fluorescence emission shift from red to green as the mitochondrial membrane loses its potential due to its damaged membrane. It was observed that FMCPT and MCPT nanoparticle treated cells have an increased green intensity (monomer-form of the dye) compared with the untreated cells which appear red (aggregated-form of the dye) [Fig 9a ]. This observation indicated that the FMCPT had more effect on the mitochondrial membrane than MCPT which suggests that the folic 
acid conjugated Mucilage nanoparticles could effectively deliver the natural compounds,Curcumin,Piprine and Thymoquinone to the breast cancer cells.Green and Red colour quantification data is also presented for both the cell lines (Fig. 9b).

a)

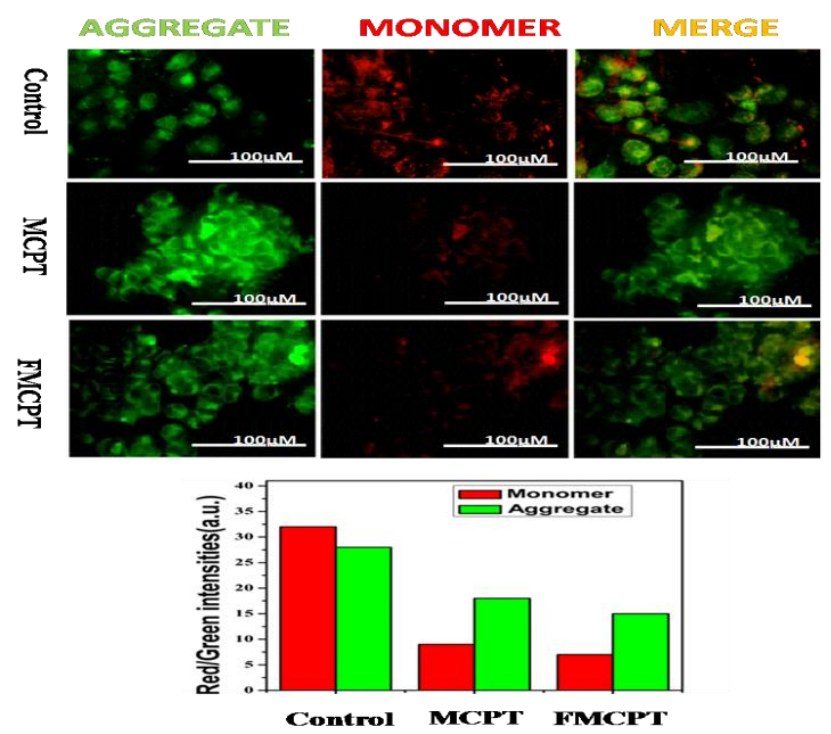

Figure.9.Mitochondrial membrane potential disruption by the delivery of natural therapeutics in MDA-MB 468 cells

\section{Conclusions}

The synthesis of biopolymeric natural compound encapsulated Okra mucilage nanoparticle is a very low cost effective process and non toxic. In this study we have observed a significant antibacterial as well as anticancer activity. This may be due to inhibit the growth of gram positive and gram negative bacteria. The Conjugated and non conjugated MNP were characterized by UV-Vis, FTIR, DLS and FESEM. The FTIR, UV-Vis spectral studies confirmed the formation of the natural compound encapsulated nanoparticles. Particle size and stabilization were determined by DLS and zeta potential techniques. FESEM studies revealed rod and uniform shaped MC,FMCP,FMCT,FMCPT nanoparticles with size in the range $25-100 \mathrm{~nm}$.

Despite a notable improvement in the field of cancer diagnosis and treatment, cancer is a growing threat to the world. Furthermore, due to high side effects caused by most promising chemotherapy, metastatic cancer needs more effective chemotherapeutics to minimize these side problems. Again, the 
global dissemination of pathogenic bacterial strains is one of the most serious present-day challenges in hospital-acquired infections which needs to be taken care of in a more economical and healthy way. The natural compound encapsulated MNPs were shown to be a potential antibacterial agent when tested against Gram-positive (S. aureus) and Gram-negative (E. coli) bacterial species which was confirmed The Curcumin-Piperine-Thymoquinone encapsulated bioplymeric Okra mucilage nanoparticles (MCPT) had more promising effect against Gram-positive (S. aureus) and Gram-negative (E. coli) pathogenic bacterial species than single compound encapsulated mucilage nanoparticles (MC,MCP,MCT) due to their synergistic effects.

Furthermore, Folic acid conjugated MNP enhances cellular ROS and causes mitochondrial membrane potential disruption in human breast cancer cells which in turn culminates in the death of cancer cells. Our results suggests that The Curcumin-Piperine-Thymoquinone encapsulated folic acid conjugated bioplymeric Okra mucilage nanoparticles (FMCPT) had more promising effect against the breast cancer cell lines than single compound encapsulated folic acid conjugated mucilage nanoparticles (FMC,FMCP,FMCT) and the non conjugated nanoparticles(MC, MCP, MCT, MCPT) due to their synergistic effects. In conclusion, our studies suggest that the natural compound encapsulated mucilage nanoparticles is not only an effective antibacterial agent but also appear as a promising anticancer drug. 


\section{References}

1. Zatz, J.L and G.P. Kushla, Pharmaceutical dosage forms-Disperse systems, M.M. Reiger and G.S. Banker, Ed; Marcel Dekker Inc.,1989, New York, 2: 508.

2. Clifford, S.C., S.K. Arndt, M. Popp and H.G. Jones : Mucilages and polysaccharides in Ziziphus species (Rhamnaceae) : localization, composition and physiological roles during drought-stress,2002. J. Experimental Botany, 53 (366) : 131-138.

3. Whistler, R.L, : Industrial gums, $2^{\text {nd }}$ Ed, 1996. Academic Press ,London.

4. Kakrani, H.K and N.K. Jain : A Study on binding properties of guggal gum, 1981, Indian J. Hospital Pharmacist, XVIII (3) : 100-102.

5. Bhunvara, N.S.and M.L. Khorana : Studies on suspending properties of Hyprophilia spinosa, 1985. Indian Drugs, $22: 500-502$.

6. Kulkarni, G.T., K. Gowthamarajan, R.R. Dhobe, F. Yohanan and B. Suresh : Development of controlled release spheriods using natural polysaccharide as release modifier, 2005. Drug Deliv, 12 : 201 206.

7. N.D. Zaharuddin, M.I. Noordin and Ali Kadivar : The use of Hibiscus esculentus (Okra) gum in sustaining the release of Propranolol Hydrochloride in a solid oral dosage form,2013. BioMed Research International 2014.

8. Ahad HA, Sreenivasulu R, Rani EM, Reddy VB (2011) Preparation and evaluation of famotidine high density gastro retentive microspheres with synthetic and natural polymers. J Pharm Educ Res 2: 110-118.

9. Y. He, Y. Yue, X. Zheng, S. Chen, Z. Du : Curcumin, inflammation and chronic diseases : how are they linked? Molecules 20 (2015) 9183-9213.

10. A. Goel, B.B. Aggarwal : Curcumin, the golden spice from Indian saffron, is a chemosensitizer and radiosensitizer for tumor and chemoprotector and radioprotector for normal organs,2010. Nutr. Cancer 62 (7) $919-930$.

11. P. Tyagi, M. Singh, H. Kumari, A. Kumari and K. Mukhopadhyay : Bactericidal activity of Curcumin , is associated with damaging of bacterial membrane, 2015. PLoS one 10 (3). PMID: 25811596 
12. N. Rainey, L. Motte, B.B. Aggarwal, P.X. Petit : Curcumin hormesis mediates a cross talk between autophagy and cell death, 2015. Cell death Dis. $6,343$.

13. U. Banik, S. Parasuraman, A.K. Adhikari, N.H. Othman : Curcumin : the spicy modulator of breast carcinogenesis, 2017. J. Exp. Clin. Cancer Res. 36, 98.

14. J. Chen, F. Wang, W. Chen : Modulation of apoptosis-related cell signaling pathways by curcumin as a strategy to inhibit tumor progression, 2014. Mol. Biol. Rep. 41, 4583-4594

15. M. Rivera, Y. Ramos, R.V. Madeline, S. Lopez-Acevedo, L.A. Cubano, J. Zou, Q. Zhang, G.Wang, N.M. Boukli, Targeting multiple pro-apoptotic signaling pathways with curcumin in prostate cancer cells, 2017, PLoS One 12 (6), e0179587.

16. S. Dragojevic, J.S. Ryu, D. Raucher, Polymer-based prodrugs: improving tumor targeting and the solubility of small molecule drugs in cancer therapy,2015, Molecules 20 , 21750-21769.

17. T. Mirakabad, F. Sadat, K.N. Koshki, A. Akbarzadeh, M.R. Yamchi, M. Mortaza, N. Zarghami, V. Zeighamian, A. Rahimzadeh, S. Alimohammadi, Y. Hanifehpour, S.W. Joo, PLGA-based nanoparticles as cancer drug delivery systems, 2014, Asian Pac. J. Cancer Prev. 15 (2) 517-535.

18. Phillips JD: Medicinal plants. Biologist 1992, 39:187-191.

19. Halawani E: Antibacterial Activity of Thymoquinone and Thymohydroquinone of Nigella sativa L. and Their Interaction with Some Antibiotics, 2009. Advances in Biological Research 3: 148-152.

20. Liu M, Koya S, Furuta H, Matsuzaki S: Growth-inhibiting activity of antraquinones and benzoquinones against methicillin-resistant Staphylococcus aureus (MRSA), 1996. Dokkyo J Med Sci ., 23:85-93.

21. Arafa el SA, Zhu Q, Shah ZI, Wani G, Barakat BM, Racoma I, El-Mahdy MA, Wani AA: Thymoquinone up-regulates PTEN expression and induces apoptosis in doxorubicin-resistant human breast cancer cells 2011. Mutat Res , 706:28-35. 
22. Inshad , A.K ., Zahid , M .M ., Ashwani , K ., Vijeshwar, V. and Ghulam , N.O . Piperine , aphytochemical potentiator of ciprofloxacin against Staphylococcus aureus, 2006 . Antimicrobial Agents and chemotherapy . $50(2): 810-812$.

23. Nwinyi, O.C. , Chinedu , N . S ., Ajani, O.O . and Ogunniran, K.O. Antibacterial effects of extracts of Ocimum gratissimum and piper guineense on Escherichia Coli and staphylococus aureus . African Journal of food sciene Vol 3 (3), 077- 081.

24. Badmaev, V., Majeed, M. And Norkus, E. Piperine an alkaloid derived from black pepper, increases serum response of beta - carotene during 14 days of oral beta-carotene supplementation, 1999. Nutr.Res. $19: 381-388$.

25. Selvcndiran , K. , Princerijeya , J. and Sakthisekaran, D. In vivo effect of Piperine on serum and tissue glycolprotein levels in benzo (a)pyrene induced lung carcinogenesis in swiss albino mice, 2009. Pulmonary Pharmacology \& Therapentic , 19 (2) : 107- 111.

26. A.D. Friedman, S.E. Claypool, R. Liu, The smart targeting of nanoparticles, Curr. Pharm. Des. 19 (35) (2015) 6315-6329.

27. K. Siwowska, R.M. Schmid, S. Cohrs, R. Schibli, C. Müller, Folate receptor positive gynecological cancer cells: in vitro and in vivo characterization, Pharmaceuticals 10 (2017) 72.

28. A. Cheung, H.J. Bax, H.J. Debra, M.K. Ilieva, G. Pellizzari, J. Opzoomer, Bloomfield J. Jacinta, M. Fittall, A. Grigoriadis, M. Figini, S. Canevari, J.F. Spicer, A.N. Tutt, S.N. Karagiannis, Targeting folate receptor alpha for cancer treatment, Oncotarget 7 (32) (2016) 525553-552574.

29. J.A. Ledermann, S. Canevari, T. Thigpen, Targeting the folate receptor: diagnostic and therapeutic approaches to personalize cancer treatments, Ann. Oncol. 26 (2015) 2034-2043.

30. B.M. Necela, J.A. Crozier, C.A. Andorfer, L. Lewis-Tuffin, J.M. Kachergus, J.X. Geiger, K.R. Kalari, D.J. Serie, Z. Sun, A.M. Aspita, D.J. O'Shannessy, J.D. Maltzman, A.E. McCullough, B.A. Pockaj, H.E. Cunliffe, K.V. Ballman, E.A. Thompson, E.A. Perez, Folate receptor- $\alpha$ (FOLR1) expression and function in triple negative tumors, PLoS One 10 (3) (2015) e0122209. 
31. K. Pal, S. Roy, P .K Parida, A. Dutta, S. Bardhan, S. Das, K. Jana, P. Karmakar : Folic acid conjugated curcumin loaded biopolymeric gum acacia microsphere for triple negative breast cancer therapy in invitro and invivo model, 2019. Materials Science and Engineering : C , 95, 204-216.

32. S. Kumari, A. K. Badana, M. Mohan G, Sailendra G, R.R. Malla : Reactive oxygen species : A key constituent in Cancer survival, 2018. Biomarker insights, 13, PMID :29449774.

33. A. Pramanik, D. Laha, A. Pramanik, S. Chattopadhyay, S.K. Dash, S. Roy, P. Pramanik, P. Karmakar, An in-vivo study for targeted delivery of copper-organic complex to breast cancer using chitosan polymer nanoparticles, Mater. Sci. Eng. C 65 (2016) 327-337.

34. D. Laha, A. Pramanik, S. Chattopadhyay, S.K. Dash, S. Roy, P. Pramanik, P. Karmakar, Folic acid modified copper oxide nanoparticles for targeted delivery in in vitro and in vivo systems, RSC Adv. 5 (2015) 68169-68178.

35. N. K. Singh : UV-spectrophotometric method development for estimation of piperine in Chitrakadi Vati, 2011. Der Pharmacia Lettre, 3(3): 178-182.

36. Yehualashet Belete and Ermias Dagne: Hptlc assay of Thymoquinone in black seed and black seed oil (Nigella sativa linn) and Identification of Thymoquinone conversion with UV-Vis, Journal of Drug Delivery \& Therapeutics; 2014, 4(4), 5-9

37. A. Maseka, E. Chrzescijanskab, M. Zaborskia, Characteristics of curcumin using cyclic voltammetry, UV-vis, fluorescence and thermogravimetric analysis, Electrochim. Acta 107 (2013) 441-447. 